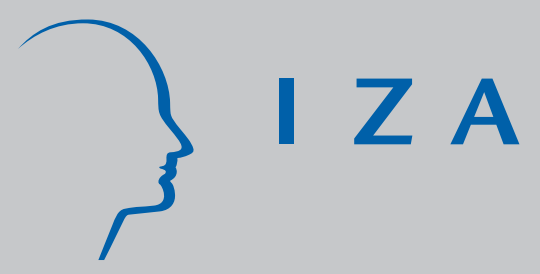

IZADP No. 2982

Far Above Rubies: The Association Between Bride Price and Extramarital Sexual Relations in Uganda

David Bishai

Shoshana Grossbard

August 2007 


\title{
Far Above Rubies: The Association Between Bride Price and Extramarital Sexual Relations in Uganda
}

\author{
David Bishai \\ Johns Hopkins University \\ Shoshana Grossbard \\ San Diego State University \\ and IZA \\ Discussion Paper No. 2982 \\ August 2007 \\ IZA \\ P.O. Box 7240 \\ 53072 Bonn \\ Germany \\ Phone: +49-228-3894-0 \\ Fax: +49-228-3894-180 \\ E-mail: iza@iza.org
}

Any opinions expressed here are those of the author(s) and not those of the institute. Research disseminated by IZA may include views on policy, but the institute itself takes no institutional policy positions.

The Institute for the Study of Labor (IZA) in Bonn is a local and virtual international research center and a place of communication between science, politics and business. IZA is an independent nonprofit company supported by Deutsche Post World Net. The center is associated with the University of Bonn and offers a stimulating research environment through its research networks, research support, and visitors and doctoral programs. IZA engages in (i) original and internationally competitive research in all fields of labor economics, (ii) development of policy concepts, and (iii) dissemination of research results and concepts to the interested public.

IZA Discussion Papers often represent preliminary work and are circulated to encourage discussion. Citation of such a paper should account for its provisional character. A revised version may be available directly from the author. 
IZA Discussion Paper No. 2982

August 2007

\section{ABSTRACT \\ Far Above Rubies: The Association Between Bride Price and Extramarital Sexual Relations in Uganda}

The custom of bride price involves the payment of goods or cash from the groom's family to the bride's family at the time of marriage. We present a theory that views bride price as a payment in hedonic markets for marital fidelity. Data from a household survey in Uganda are used to test the theoretical prediction that payment of bride price will be associated with fewer non-marital sexual relationships for women. The data show a robust association between bride price payment and lower rates of non-marital sexual relationships for women but not for men.

JEL Classification: D13, I12, J13, O15

Keywords: marriage, extra-marital relations, bride price, Uganda

Corresponding author:

David Bishai

Department of Population and Family Health Sciences

Johns Hopkins University Bloomberg School of Public Health

615 N. Wolfe St.

Baltimore, MD 21030

E-mail: dbishai@jhu.edu 


\section{"Who can find a virtuous woman? For her price is far above rubies." --Proverbs 31:10}

\section{Introduction}

Existing economic studies of extramarital relations or marital fidelity are confined to Western data (Fair 1978; Lemennicier 1982; Yen 1999; Cameron 2002). The research reported here breaks new ground by applying an economic framework to the study of extramarital relations in an African country. Ugandan rates of extramarital relations don't differ dramatically from those in the U.S. ${ }^{1}$ However, like many other Africans, Ugandans differ from Westerners in frequency of monetary bride price payments prior to marriage. Anthropological evidence from Uganda reports that husbands are considered as owners of sexual rights over their wives, that unauthorized sexual contact between a married woman and another man is considered to be theft committed against her husband, and that bride price transfers rights over a woman's sexuality (Parikh, 2007). In this paper we use Ugandan data to test links between payments between spouses or their families and the extramarital behavior of husbands and wives.

We first present a theoretical framework based on Demand and Supply (D\&S) and assumptions that are congruent with some of this anthropological evidence. From here we derive the predictions that men's payment of a bride price reduces the likelihood that women engage in extra-marital relations, without simultaneously decreasing the likelihood that men engage in such relations. Our model is in the tradition of previous D\&S models whose focus it was to explain the prevalence of bride price or dowry, including models by Bronfenbrenner (1971), Becker (1973, 1981), Grossbard (1978), Grossbard-Shechtman (1983,1993), Papps (1983), Rao (1993), Jacoby (1995), Botticini (1999), Zhang and Chan (1999), Botticini and Siow (2003), Anderson (2003), and Arunachalam and Logan (2006). It also relates to D\&S models of marriage applied to the analysis of other behaviors, such as Becker's (1973) analysis of polygamy or Choo and Siow's (2006) research on couple formation by age.

Our study of the consequences of bride price payments for marital fidelity is reminiscent of economic studies of other consequences of dowry or bride price payments. For instance, Zhang and Chan (1999) have studied the degree to which Taiwanese husbands help their wives as a function of whether bride price was paid at marriage. Our economic approach stands in contrast to existing studies of extramarital relationships in Africa that have taken epidemiological and anthropological perspectives, with little recognition of individual costs and benefits of sexual fidelity (Kimuna and Djamba, 2005, Onah, et al., 2002, Slaymaker and Buckner, 2004).

We test our predictions with data from a household survey conducted in the capital city Kampala and 12 rural districts of Uganda in 2001. We find that if a bride price was paid, women are less likely to have extra-marital relations, but the same is not true for men.

\footnotetext{
1 According to nationally representative samples, in the US in $20024.5 \%$ of married men and $15.6 \%$ of cohabiting men had more than 1 sex partner in the last 12 months (the corresponding figures for U.S. women were respectively $3.8 \%$ and $15.2 \%$ ), whereas in Uganda in 2001 12\% of married men and 3\% of married women had extramarital sex in the last 12 months Uganda Bureau of Statistics (2001)Uganda Bureau of Statistics and ORC Macro (2001) Uganda demographic and health survey 2000-2001. UBOS and ORC Macro, Calverton, MD.
} 


\section{Theoretical Framework: Bride Price and Extra-Marital Relations}

It is assumed that unmarried males $i$ and females $j$ are searching for a spouse and prefer one who will be faithful to them. The preference that a spouse be faithful can in part be attributed to biological theories of genetic fitness such as Trivers (1972). In systems of bi-parental care, female fitness is enhanced by exclusive access to male resources and male fitness is enhanced when female behavior raises the odds that his resources will benefit his own biological offspring. We view a partner's fidelity as a private good, for only one individual enjoys it and that individual's utility from having a faithful spouse can be separated from that of the partner's utility.

Being faithful entails an opportunity cost, namely the value of foregone alternative relationships. Related biological theories imply that both males and females would rather not be faithful themselves. For females, extra-pair mating helps to diversify the portfolio of genetic contributions to their offspring (Mennill, et al., 2003). For males, extra-pair mating not only diversifies, but can increase the number of offspring (Willis, 1999). Accordingly, we assume that for both men and women a partner's fidelity thus enters positively in an individual's utility function, whereas own fidelity enters that utility function negatively. (For simplicity, we ignore the public goods aspects of fidelity on the well-being of children and on the trust that enables coordinated decisions).

In this model both men and women have the task of choosing which partner to marry and negotiating with that partner (and her guardians) the amount of infidelity that will occur. It is also assumed that marital negotiations between two individuals (or their representatives) can lead to binding agreements or marital contracts (see Cigno 1990; Laferrere 2001). In this case, the contracts regard frequency of future extra-marital relations and may involve monetary transfers. What makes the agreements binding are commitment devices. In the Ugandan context marriage contracts often include bride price and contract enforcement is aided by bride price refundability. Even though it is officially illegal to request the refund of bride price in Uganda (Government of Uganda, 2001), if a wife is not faithful, a husband can claim his money back and return his wife to her male relatives. Refundable bride price payments thus work as incentives for women to be faithful and can be seen as reflecting a power asymmetry in favor of men. ${ }^{2}$ A second cultural tradition in Uganda is to spread bride price payments over a period of time spanning both before and after the wedding. The timed payments provide renegotiable terms that can reinforce men's pre-marital promises because husbands who honor their commitments might obtain more favorable terms for their post-marriage bride price payments than husbands who renege.

The following model is symmetrical for both sexes, but we present it in detail only

from the male perspective. A representative man of type $i \in M$ considers possibly forming a couple with women of different types defined by age, ethnicity, or education. The man faces a social and biological constraint $\bar{N}_{m}$, the maximum number of potential extramarital partners

\footnotetext{
2 A recent study performed in Uganda suggests that by paying a bride price, men also increase their power to abuse women: payment of bride price emerged as one of the factors associated with domestic violence (see Kaye DK, Mirembe F, Ekstrom AM, Kyomuhendo GB, Johansson A (2005) Implications of bride price on domestic violence and reproductive health in wakiso district, Uganda. Afr Health Sci 5(4):300-3..
} 
that can possibly be obtained by a man $m$ of any type (a similar constraint $\bar{N}_{f}$ influences the decision of a woman $f$ of any type). The maximal number of infidelities is expected to vary cross-culturally. ${ }^{3}$ The actual number of extramarital partners of a wife and husband in an $i j$ match, $N_{i j}^{+}$and $N_{j i}^{+}$, depends on the personal feasibility constraints:

$$
N_{i j}^{+}=\bar{N}_{m}-N_{i j}^{-} \text {, }
$$

where $N_{i j}^{-}$are men's avoided infidelities and $\bar{N}_{m} \geq N_{i j}^{-} \geq 0$, for men of type $i$, and

$$
N_{j i}^{+}=\bar{N}_{f}-N_{j i}^{-} \text {, }
$$

where $N_{j i}^{-}$are women's avoided infidelities, for women of type $j$.

If $N_{i j}^{-}=0$ or $N_{j i}^{-}=0$ the individual has the maximum number of extramarital partners.

Were he to form a couple with a representative woman of type $j \in F$, a man would derive utility from supplying his infidelities $N_{i j}^{+S}$ and obtaining $N_{j i}^{-D}$, the number of extramarital partners that his potential wife avoids (her fidelity). We simplify further by assuming that individuals only consume marital fidelity and a composite good $X$ consumed privately. ${ }^{4}$ An individual man's utility function thus takes the form

$$
V_{i}=V_{i}\left(N_{i j}^{+}, N_{j i}^{-}, X_{i j}\right)
$$

The double subscripts convey the idea that individual willingness to demand or supply fidelity and to consume other goods depends on the characteristics of both partners in a couple. Our assumptions imply that

$$
\frac{\partial V_{i}}{\partial N_{i j}^{+}}>0, \frac{\partial V_{i}}{\partial N_{j i}^{-}}>0, \frac{\partial V_{i}}{\partial X_{i j}}>0 \text {. }
$$

Individuals in the marriage market are constrained by their own income, the value of their own fidelity to potential partners of the opposite sex, and the value of these potential partners' fidelity. We model these values as costs per avoided extra-marital relation. We denote these costs as $C_{j i}$, what a woman of type $j$ charges per avoided extra-marital relation if married to a man of type $i$, and $C_{i j}$, what a man of type $i$ charges per avoided extra-marital relation if married to a woman of type $j$. These costs are given to individuals in the sense that they are beyond their control (more below on how they are established). For a representative man in an ij match the budget constraint is:

$$
C_{i j} N_{i j}^{-}+Y_{i}=C_{j i} N_{j i}^{-}+P X_{i j}
$$

where $Y$ is individual income, and $P$ is the price of $X_{i j}$. Thus a man's full income includes the monetary value of his avoided infidelities to his spouse plus his monetary endowment $Y_{i}$. The man must allocate his spending between buying avoided infidelities from

\footnotetext{
${ }^{3}$ Even Mozart and his librettist DaPonte recognized the possibility that maximal infidelities could differ geographically. In Leporello's aria it emerges that Don Giovanni had 740 extramarital conquests in Italy, 231 in Germany, 100 in France, 92 in Turkey, but in Spain-1003.

4 The analysis could be expanded to include other private goods or services (such as agricultural home production) or homeproduced public goods (such as a shared home or shared children) possibly produced in marital household production. More on public goods produced in marriage can be found in Weiss and Willis (1985) and Lam (1988).
} 
his wife and the composite commodity, $X_{i j}$ Maximization of utility subject to the budget and feasibility constraints leads to the following equilibrium condition for a representative man in an $i j$ match:

$$
\frac{\partial U / \partial N_{i j}^{+}}{C_{i j}}=\frac{\partial U / \partial N_{j i}^{-}}{C_{j i}}=\frac{\partial U / \partial X_{i j}}{P}
$$

This leads to a man's derived demand for a wife's fidelity $N_{j i}^{-}$(the infidelities a potential wife is willing to avoid) and his supply of $N_{i j}^{-}$to a potential wife, i.e. the infidelities he is willing to avoid.

A symmetric maximization leads to a woman's derived demand for a potential husband's fidelity $N_{i j}^{-}$and her supply of the infidelities $N_{j i}^{-}$that she is willing to avoid. Individual supplies are expected to be upward-sloping with a terminus at upper-bound $\bar{N}_{m}$ or $\bar{N}_{f}$. Individual demands are expected to be downward-sloping due to the law of diminishing marginal utility.

Were an $i j$ marriage to form, it would involve two simultaneous matches at given costs $C$ and $P$ : (a) between the quantity of fidelity that a woman is willing to supply to a husband and the quantity of a wife's fidelity that a man demands, and (b) between the quantity of fidelity that a man is willing to supply to a wife and the quantity of a husband's fidelity that a woman demands. Such a marriage would involve the following net transfer from husband to wife: $T_{j i}=C_{j i} N_{j i}^{-}-C_{i j} N_{i j}^{-}$, i.e. the difference between what men are willing to pay for women's fidelity and what women are willing to pay for men's fidelity.

A positive bride price $B$ implies a positive monetary transfer $T$ from groom to bride's family. We view the bride price that a man of type $i$ is willing to pay for a wife of type $j$ as a positive monotonic function of the present value of these net transfers:

$$
B_{j i}=F\left(T_{j i}\right)=F\left(C_{j i} N_{j i}^{-}-C_{i j} N_{i j}^{-}\right),
$$

where $F$ includes a calculation of discounted value.

In countries like Uganda there are no negative bride prices, so $B$ is restricted to be nonnegative. In principle, there could also be dowry payments that involve negative $B$ s and consist of contracts exchanging excess male fidelity for money paid by women to their husbands' relatives. However, we don't know of societies where relatives control their grown sons' marital fidelity and women or their relatives can request that a dowry be reimbursed in case the husband turns out to be unfaithful, so our model is restricted to cases of bride price. This net transfer could also be zero: husbands' payments to wives may exactly balance out the payments of these wives to the husbands, implying $C_{i j} N_{i j}^{-}=C_{j i} N_{j i}^{-}$and budget constraints collapsing to $Y_{i}=P X_{i j}$ in the case of men and to $Y_{j}=P^{\prime} X_{j i}$ in the case of women ( $Y$ and $P^{\prime}$ are respectively the income and prices faced by women, and $X_{j i}$ are the goods bought by women).

If a bride price is paid, male "payments" for female fidelity $\left(C_{j i} N_{j i}^{-}\right)$are high relative to female "payments" for male fidelity $\left(C_{i j} N_{i j}^{-}\right)$, and costs of infidelity avoidance $C$ are given, this implies a higher amount of $N_{j i}^{-}$, i.e. more infidelity avoidance by wives, and/or a lower amount 
of $N_{i j}^{-}$, infidelity avoidance by husbands. Accordingly, we view bride price payments as part of contracts that involve the exchange of men's payments to the brides' male relatives prior to marriage, in return for promises of excess infidelity avoidance on the part of brides and their male guardians (in excess of parallel promises by grooms).

Men of type $i$ can choose among $J$ possible $i j$ matches, and women of type $j$ can choose among $I$ possible $i j$ matches. There are thus $I \times J$ possible types of matches and $I \times J$ pairs of hedonic marriage markets. Not all $i j$ combinations may have a market: there may be cases of bilateral monopoly (if there is only one man $i$ and one woman $j$ ) and some demands or supplies may be zero. ${ }^{5}$ In each hedonic market all of the men's demands for a potential wife type's infidelity avoidance are added up. The market can allow for the possibility that men have more than one wife. The supplies of all individual women willing to be faithful to potential husbands of a particular type are also added.

Competition between the many men of type $i$ and the many women of type $j$ leads to the establishment of equilibrium quantity $N_{j i}^{-}$and price $C_{j i}$ in each market for women's infidelity avoidance, and equilibrium quantity $N_{i j}^{-}$and price $C_{i j}$ in each market for men's infidelity avoidance. Whether we use $\mathrm{D} \& S$ to analyze more conventional markets such as labor markets, or markets for avoided infidelities, we need to be alert to the existence of two dimensions of aggregate quantity: a participation dimension and a level of participation for the individuals who participate. Equilibrium conditions in each pair of markets are established simultaneously and interdependently, as each individual man and woman participates simultaneously in markets for female and male infidelity avoidance.

A general equilibrium obtains, as demands for infidelity avoidance of various types of potential spouses are interrelated. (Both demands and supplies vary with opportunities to substitute between various kinds of spouses). Across the population we expect that where a positive bride price $B$ was paid it is more likely that there was a contract involving male payments in return for more future female infidelity avoidance. Given the feasibility constraints, such contracts regarding the exchange of bride price for infidelity avoidance $N^{-}$translate into an observed association between reports of bride price payment and fewer reported infidelities $N^{+}$. More specifically, we predict that

Wife's observed infidelities and bride price B paid prior to marriage will be negatively correlated across markets for various ij types. In contrast, busband's observed infidelities and bride price will be positively correlated across ij types.

These predictions are based on the definition of fidelity as a private good. The more marital fidelity is viewed as a marital public good, the more we expect to observe a positive correlation between the faithfulness of both husbands and wives, regardless of bride price. Our predictions would also differ if costs $C_{i j}$ or $C_{j i}$ were allowed to vary across the hedonic markets for different types of men and women.

\footnotetext{
${ }^{5}$ In a particular application of a market analysis of marriage between men and women categorized by age, Choo and Siow (2006) found many age combinations of men and women to have zero values.
} 
Our goal in the empirical section is to estimate both male and female marital fidelity as a function of whether a bride price was paid at the time of marriage. When estimating how marital fidelity is associated with bride price, we want to include male and female personal characteristics that are also likely to be associated with marital fidelity. A study by Cameron (2002) based on U.K. data found that wealth, higher education, and church attendance had a positive effect on married men's participation in extra-marital relations, but not on married women's. Accordingly, we will be including wealth and education (of both spouses) in our regressions. We also control for husband's farmer status. The same U.K. study also found that women most likely to participate in such relations had recently moved into their area of residence and worked long hours, but these variables did not explain British men's extramarital relations. Accordingly, we include a variable about husband's absence in wives' regression of marital infidelity. Yen (1999) used U.S. data, previously analyzed by Fair (1978), to calculate maximum likelihood estimates of both participation in extra-marital relations and level of such relations. He found that years of marriage, presence of children, and religiosity affected participation in extramarital relations or its level. In contrast, education had a positive effect on participation in extramarital relations and a negative effect on level.

We expect age to also be a factor associated with marital infidelity, as it is likely to be related to opportunities for infidelities and to the presence of contracts involving the exchange of bride price for fidelity. Bride price can be also be seen as an attempt to compensate fathers for the loss of daughters' labor contributions and would therefore be a positive function of women's labor productivity (Kressel, 1977). In addition, we also include as a determinant of having bride price whether the wife perceives a high risk of AIDS (the higher those risks, the higher the health cost of infidelities).

\section{Data and Methods}

\subsection{Data}

We test these predictions with data from a household survey conducted in Kampala and 12 rural districts of Uganda in 2001. The primary purpose of the survey (described in detail elsewhere) was to measure the willingness to pay for an AIDS vaccine (Bishai, et al., 2004). Since the perception of HIV/AIDS risk is an important component of the demand for an AIDS vaccine, the survey included a module to assess respondent's risk of HIV/AIDS via sexual behavior, including numbers and types of extramarital sexual partners and use of condoms. In addition, all currently married women were asked whether money or valuable items were transferred to their family by way of bride price. They were also asked the date of completion of the payment and the total value of the payment.

In 1999, Uganda's Bureau of Statistics prepared a sampling framework in every district of the country in preparation for the 2000 Demographic and Health Survey (DHS) (Uganda Bureau of Statistics and ORC Macro, 2001). The survey we analyze here was carried out 12 months after the DHS survey left the field in the sampling framework of that survey. In the first stage, Kampala (the capital) was selected as well as a sample of 11 additional outlying districts. The target districts were selected to offer wide variation in the rate of perceived risk (based on responses to the DHS of 1995) and income levels.

In each household, a household respondent was identified who completed a household roster and identified the principal economic activity of the household head as well as the 
principal assets owned. From the household roster, a maximum of 3 adult respondents per household were selected for the in-depth interview on behavior and attitudes about AIDS and AIDS vaccines.

A total of 1,532 households were targeted and all locations visited. Of these, interviews were conducted in 1,215 households containing a total of 6,378 residents. Of these, 2,426 individuals were eligible for the questionnaire. To be interviewed, a respondent had to be a usual resident of the household, aged 18-60, and not absent for more than 6 months in the previous 12 months. A total of 1,758 individual interviews were conducted. There were 839 interviews with currently married women, and 430 interviews with the husbands of interviewed women. Husbands were only interviewed by male interviewers, wives by female interviewers. All interviewers were experienced field staff from Makerere University who received extensive training in the protocol and were supervised with 1 field supervisor for every 4 interviewers. Unfortunately, 247 women did not answer whether or not bride price was paid to them-the Western region accounted for nearly half of the refusals. In the current analysis we eliminate these 247 women with missing bride price data from the analysis. Ultimately there were 552 married women with valid observations of both women's self-reported infidelity and selfreported bride price and there were 340 valid observations of matching husband's self-reported infidelity bride price payment and other husband's characteristics.

Only 157 respondents provided nominal estimates of the size of their bride prices and the year payment was completed. This is not a sufficiently large number of observations to justify using the level of the paid bride price in our analyses. We only use a dichotomous variable: whether a bride price was paid or not.

Table 1 lists the characteristics of the women and men in the analytical sample. Table 1 shows that $5 \%$ of wives and $19 \%$ of husbands had non-spousal sex during the prior 12 months. The sample of only the 340 wives whose husbands were also interviewed had the same rates of non-spousal sex (not shown in table). The overall prevalence of bride price was $68 \%$ in the 552 women studied. There were period effects: the prevalence of bride price declined with age from $91 \%$ for women $50-60$; to $72 \%$ for women $30-49$ and $63 \%$ for women age $18-29$ reporting bride price (not shown in table). Data not used in our study also indicates that there was wide variation in the timing of bride price payments: in the case of six respondents bride price was reportedly paid prior to a girl's birth, and for an additional 13 women bride price was paid prior to a girl's $10^{\text {th }}$ birthday. The median age of the wife at the time that bride price was paid in full was 18.

We explored different ways to measure schooling including highest grade completed and its quadratic, dummies for each grade attained, and a more parsimonious ordinal schooling measure which coded all individuals with 0 years of schooling as 0,1-4 years of schooling as 2.5 , all with 5-7 as 6 , all with 8-11 as 9.5, all with $12-13$ as 12.5 , and all with over 13 as 13 . We also explored the use of models with either schooling attainments of both spouses or the schooling attainment of one spouse together with the difference in attainments between spouses. Finally, we experimented with models including the parsimonious ordinal schooling measure and its quadratic term, to investigate possible non-linearities in the association between schooling and infidelity, as well as schooling and bride price. These different measures are available in an appendix (Bishai and Grossbard, 2007).

Within the constraints of a thirty minute interview, we could only ask about ownership of a brief list of assets. We explored many ways to analyze the asset list, including factor scores and raw counts of assets. Ultimately, the models were robust to these different treatments of 
the asset variables and we settled on a simple dichotomous indicator equal to 1 for households that owned more than 3 assets from the asset list.

As is evident from Figure 1, there is wide variation in the frequency of extra-marital relations within Uganda. We therefore control for region in our regressions. In three western districts of Uganda, cultural tradition is particularly strict in sanctioning female marital infidelity with harsh punishments including death. Among the 151 women from western Uganda in our sample there were essentially no reports of marital infidelity (See Figure 1). It is unclear whether this reflects the outcome of a coercive cultural regime, an understandable reluctance to report these activities to interviewers, or both. Given those dramatic regional differences, in our regressions we explore the possibility that the association between bride price and extramarital relations depend on whether individuals live in the west or not by including an interaction term between bride price and the dummy for residence in western Uganda.

\subsection{Statistical Specifications}

In order to preserve maximum sample size while including husband's characteristics in models predicting wife's behavior we chose to do all of the following: a) run models without any husband's characteristics, b) run models including husband's characteristics despite the reduced sample size, and c) run models in which husband's characteristics were imputed by regressing each variable on all other right-hand-side covariates. After determining that the coefficient on brideprice did not vary by more than $14 \%$ regardless of the strategy and that its statistical significance was improved from a $p$-value of 0.07 to 0.01 in models where husband's characteristics were imputed, we opted for models based on imputed data.

Our major goal is to estimate regressions of marital infidelity. Our predictions about the associations between bride price and marital infidelity were stated in terms of the number of infidelities $N^{+}$. We now introduce a dichotomous variable $N^{*}$ which is defined as the probability of participating in any extra-marital relations in the past 12 months, since we have data on participation but not on number of infidelities. We expect women's $N^{*}$ to be negatively related to another dichotomous variable, $B^{*}$, whether or not bride price was paid at the time of marriage. We first state the infidelity probability of the " $b$-th" wife of type $j$ as a linear function of $B^{*}$, characteristics of the wife $X_{h}$, and characteristics of the husband $X_{g}$ :

$$
N_{j i h g}^{*}=c+\gamma_{1} B_{j i h g}^{*}+\gamma_{2} X_{h}+\gamma_{3} X_{g}+\eta_{j i h g}
$$

$N_{j i h g}^{*}$ is the probability that the " $h$-th" wife of type $j$ participated in an extra-marital

affair while married to the " $g$-th" husband of type $i$. Subscripts $i$ and $j$ indicate that each male type and female type participate in one of the $I \times J$ marriage markets, and each of these markets influences actual bride prices, and therefore the likelihood that a bride price is paid.

Likewise, $N_{i j g h}^{*}$ is the probability that a particular husband of type $i$ participated in an extra-marital affair while married to a particular wife of type $j$, and we have the linear function

$$
N_{i j g h}^{*}=c+\beta_{1} B_{j i h g}^{*}+\beta_{2} X_{h}+\beta_{3} X_{g}+\mu_{i j g h} \text {, }
$$
variables.

which also includes a dichotomous bride price variable as one of the right-hand-side

With dichotomous reports of infidelity as indicators of $N^{*}$, it would be natural to use probit models to estimate the probability of extramarital sexual relations. Indeed, a bivariate 
probit model could be used to model a non-zero covariance, i.e. $\operatorname{Cov}\left(\eta_{\text {jihg }} \mu_{\mathrm{ijgh}}\right)>0$. We first tried models applying the bivariate probit and obtained an insignificant rho statistic, thus leading us to reject the hypothesis that $\operatorname{Cov}\left(\eta_{\text {jing }} \mu_{\mathrm{ijgh}}\right)>0$. We then proceeded to estimate probit models applied to one spouse at a time. These models forced the exclusion of the 151 women from the western regions who reported no extramarital relations. If a model contains a dummy variable for a group which shares common values of the dependent variable, this group dummy coefficient cannot be estimated by probit or logit models. Ordinary Least Squares (OLS) models that assume linear probability are not sensitive to this problem (Caudill, 1988). We therefore estimated OLS models of marital infidelity that enabled us to preserve sample size, even though some predicted probabilities from an OLS model would be outside the 0-1 interval. Both the probit and OLS model give significant coefficients on the relationship between bride price and wife's extramarital affairs, but the advantage of the OLS results is that they include the Western region. This allowed us to estimate models that include an interaction between 'bride price' and 'West' and attain higher statistical significance, as presented in Table 2 and discussed in the next section. Bivariate and single equation probit results, without the interaction term, are presented in the appendix (Bishai and Grossbard, 2007).

To improve interpretation of the association between bride price and infidelity, we need to understand how background spousal features are correlated with having bride price. Thus, we estimate regressions of the dichotomous report of whether bride price was paid. Our linear equation of the determinants of whether a bride price was paid, $B_{j i h g}^{*}$, is:

$$
B_{j i h g}^{*}=c+\delta_{1} X_{h}+\delta_{2} X_{g}+\varepsilon_{i j g h}
$$

We also tried to include marriage market level variables for each market involving a match $i j$, and not only individual background attributes $X_{h}$ and $X_{g}$. Two possible market level variables are sex ratio and regional prevalence of polygyny. ${ }^{6}$ Past research has shown a negative association between dowry, another form of premarital payment, and sex ratio (the ratio of men to women) documented e.g. for contemporary India (Rao, 1993) and medieval Tuscany (Botticini, 1999). However, since there has not been a recent census in Uganda, there are no reliable data on sex ratio per region. Cross-cultural comparisons have viewed polygyny as one of the factors associated with men's heightened demand for wives, and therefore with the existence and size of bride price. The districts of Uganda reflect an amalgam of more than 20 different ethnic groups (Nzita and Niwampa, 1998). Ethnic variation is one of the reasons that polygyny rates vary throughout Uganda. Consequently, we estimated some regressions with information on regional polygyny rates and included ethnicity dummies.

Even though the decision to pay bride price precedes the occurrence of marital infidelity, our theory suggests that bride price is likely to share unobservable determinants with marital infidelity. We thus attempted to estimate structural equations of both marital infidelity and bride price. This requires at least one good instrumental variable that is correlated with bride price but exogenous to marital fidelity. Unfortunately all of the personal characteristics like age, education, and occupation would make poor instruments for bride price because these factors also influence the attractiveness of husband and wife to extramarital partners. With sex ratio information unavailable, we explored the usefulness of regional rates of polygyny and

\footnotetext{
${ }^{6}$ Polygyny is often called polygamy. Anthropologists distinguish polygyny (multiple wives) from polyandry (multiple husbands). For evidence on such positive association among the Sebei of Eastern Uganda see Goldschmidt (1974).
} 
ethnicity dummies as instruments for bride price. However, a priori one might be hesitant to assume that ethnicity and polygyny are uncorrelated with marital infidelity through any other means than bride price because ethnic norms that regulate the social consequences of infidelity are likely to be related to norms regarding rates of polygyny. It would have been helpful if there had been some credibly exogenous shocks to bride prices, such as a natural experiment or policy intervention, but none of these were available.

In a fruitless search for plausible instruments for bride price we tested whether within our Ugandan sample regional polygyny rates are related to whether a bride price was paid. We found a very low correlation. Both two-stage least squares and bivariate probit specifications, that included markers of ethnic variation and district level polygyny as potential instruments for bride price, failed tests for weak instruments, in addition to their questionable exclusion restriction. We thus abandoned attempts to use instrumental variables for bride price and do not present these estimates. The estimates we do present are associations and not causal estimates and will not be interpreted as such.

\section{Results}

Figure 1 shows a preliminary analysis of the relationship between bride price and infidelity in the form of a scatter plot of rates of each event within the 13 districts surveyed. Panel A depicts correlations between bride price prevalence and women's marital fidelity rates at the district level. The slope of a regression line in Figure 1, panel A, would be $-0.102(p=0.104)$, suggesting a negative relationship. This figure also indicates how women in western districts reported zero extramarital relationships. Panel B presents similar correlations between bride price and men's marital fidelity. A quadratic in bride price could be fit in panel B with a coefficient of $1.85(p=0.11)$ on bride price prevalence and $-1.51(p=0.10)$ on bride price prevalence squared. With only 13 data points the statistical significance of an ecological analysis remains limited.

One can also begin to appreciate the relationship between bride price and infidelity from the descriptive statistics presented in Table 1. A comparison of the last two columns in Table 1 indicates that $2 \%$ of women with bride price reported infidelity, compared to $10 \%$ of women without bride pride reporting infidelity. This ratio of 1 to 5 is statistically significant. The same two columns in Table 1 also indicate that male infidelity rates are higher $(21 \%)$ in unions with bride price, compared to $(16 \%)$ in unions without bride price, but this difference is not statistically significant.

We now discuss our regression results. For reasons explained above, none of the models presented in this paper are based on an instrumental variables approach. Our results must be interpreted as indicative of correlation, not causation. Table 2, Model A, shows the results of a linear probability model of an individual woman's probability of reporting nonspousal sexual contact in the last 12 months. Model A shows that having bride price is associated with a woman's probability of infidelity that is 0.08 points lower, controlling for both spouse's age and schooling and a number of other characteristics. Model B shows that bride price had a positive but not statistically significant association with the probability of male infidelity.

Our results show non-linear associations between marital fidelity and schooling. According to Model A, each additional year of wife's schooling increases the probability of her infidelity if she has between 0 and 4 years of schooling. However, an additional year of schooling lowers the probability of her infidelity if she has more than 4 years of schooling. 
Model B shows that for husbands the net "effect" of a year of schooling is to decrease the probability of infidelity for men who have between 0 and 5 years of schooling, and to increase the probability of infidelity for those who have more than 5 years of schooling.

We also estimated alternative specifications using probit models (Bishai and Grossbard, 2007). The alternative specifications did not substantially alter the results shown in Table 2 , with one exception: when a bivariate probit model of the probability of wife cheating was estimated simultaneously with a bride price determination model, using community ethnic group indicators as instruments, the instrumented bride price showed no significant relationship to female infidelity. However the instrument set was weak and the estimate of "rbo", the correlation between the two equations in the bivariate probit model, was insignificant, suggesting that the model was mis-specified.

Unobservable heterogeneity between women with and without brideprice could account for some of our findings. If bride price simply marks out more traditional women who adhere to old-fashioned sexual norms, then including a variable for schooling should be a better proxy for traditionalism and the effects of bride price on infidelity should be weakened and diminished. In non-reported models of wife's infidelity that excluded schooling the coefficient of bride price was 0.089 ( $t$-statistic -2.84), which is almost identical to the 0.087 obtained in model A that includes schooling. Bride price thus does not seem to be associated with infidelity simply because it signals traditionalism.

Our finding of a negative association between women's marital infidelity and bride price is robust to the inclusion of additional variables not shown in Table 2. Prior work with the same data estimated models that had ethnic composition, particularly heterogeneity, as determinants of infidelity (Bishai, et al., 2006). Including ethnic dummies in addition to brideprice did not change the association between infidelity and bride price. Community amenities such as distance to a market and a scale for urbanicity also had no important effects on the level or significance of the brideprice variable. Rates of wife's infidelity were higher $(13.8 \%)$ for households with only one child compared to $4.5 \%$ in households with more than one child. This difference in infidelity by number of children was only significant in bivariate analysis $(p=0.01)$, but not in multivariate regression models. Including the number of children did not change the association between bride price and infidelity. Our basic result is also robust to different definitions of schooling. We obtained similar results when estimating alternative regressions of infidelity omitting quadratic terms in schooling, including spousal schooling differences, and coding schooling categories as dummies.

We assessed a possible non-response bias. In the sample of women who did not respond to the infidelity question, the proportion having bride price was $76 \%$. Thus the nonresponding women appear to be somewhat more traditional. It is speculative to suggest how including these women would have changed the results, but we nevertheless conducted an experiment to see what happens if the non-responders were recoded as all unfaithful or as all faithful. If all of the 38 women who did not respond to the infidelity question are recoded as being unfaithful, the coefficient on bride price is reduced to $-0.071(t$-statistic $=-1.82)$. If these 38 women with no response are recoded as being faithful (which is more likely, since a vast majority of women in our sample were faithful) the coefficient becomes -0.083 ( $t$-statistic 2.84). This exercise suggests that excluding the women who did not report their fidelity (as we did in our estimations) leads to similar results as those obtained if these respondents were all faithful.

Models $\mathrm{C}$ and $\mathrm{D}$ of Table 2 show the correlates of the likelihood that bride price was paid. The difference between Model C and Model D of Table 2 is that Model D includes 
markers for ethnic group. Bride price is associated with households involved in farming and is significantly less common in the urban setting of Kampala. It is also associated with a higher probability that the wife will state that she perceives no risk of AIDS. The inclusion of the ethnic group markers accounts for a modest increase in $R^{2}$ of 0.02 points.

\section{Conclusions and Implications}

Our major finding is that payment of a refundable bride price is associated with reduced participation in extra-marital relations by women, but not by men. Even though the data do not support the inference that bride price payments cause female marital fidelity, the negative association between bride price payment and wife's infidelity is consistent with our model that views men and women (and their male guardians) as establishing contracts involving the exchange of bride price payments in return for promises of brides' future sexual fidelity.

At the same time, our model assumes that individuals prefer more sexual freedom for themselves. Paying for their wife's fidelity in the form of bride price may reduce men's need to exchange vows of sexual fidelity with their brides in order to obtain their fidelity. As expected from our analysis, and in contrast to the association that we find between bride price and women's fidelity, we find no evidence of a negative relationship between paying bride price and men's fidelity in marriage.

Our model carefully states the behavioral assumptions behind such money-for-fidelity exchanges and is compatible with economic models of marriage based on Demand and Supply analysis. It also recognizes that such contracts entail gender asymmetry in marital power. It is consistent with our interpretation that bride price is refundable in Uganda, and that wife's $e x$ post marital infidelity is considered a valid reason for bride price refunds. In Africa in general, and in Uganda in particular, there has been active policy discussion about abolishing the refundability of bride-price. It has been argued that such refundability enables men to control their wives by threatening to divorce and request a refund of the bride-price (Okioma, 2004, Rogers, 2004, Wendo, 2004). Our analysis reinforces such arguments by stating them in the language of prices, markets, and other economic concepts.

Further empirical research on this topic is needed. It would help to have more detailed information on bride price payments from Uganda or elsewhere, and more data that make it possible to estimate structural systems containing valid statistical instruments. Future work could also offer more in-depth exploration of the effect of education on use of bride price and the connection between bride price and sexual fidelity. What is the reason that after a certain level of education more educated women are less likely to have extra-marital relations, but the opposite is true for more educated men past a certain level of education? Are women using their higher education to match with men who promise to reciprocate fidelity, but not so with men?

Our analysis also has implications for the theoretical literature on economics of marriage and the family. Following Becker $(1973,1981)$ this literature tends to think of all that is produced in marriage as public goods. This makes sense in the case of decisions regarding children. The assumption that individual time spent on home production is a public good is less compelling. Some, including Grossbard-Shechtman (1993), have conceived of goods that are privately produced and consumed by married individuals, without specifying the nature of such goods. Our analysis here has focused on the "private good" side of sexual relations. Given the prevalent preference for exclusive sexual partners and often observed reluctance to supply 
exclusivity, this study strengthens the argument that some private goods are produced in marriage by offering a concrete example.

Another possible direction for future work is to explore the effects of various institutional arrangements regarding the timing of bride price payments. In theory, a woman and her guardians have the option of renegotiating the timing of bride price payments, which could empower women. So far, our limited information on timing of actual payments in Uganda conveyed little evidence that such options are exercised: most bride prices were fully paid off by the time the bride was 20 years old. Cross-cultural comparisons could also contrast societies that have no premarital payments, societies with bride price systems, societies with dowry systems, and societies that have both. How common is it that any form of marital behavior correlates with bride price or any other payment system? Our suggestive results for Uganda could be compared with many other results, including those of Zhang and Chan (1999) for Taiwan. Possible parallels between our main finding and that of Zhang and Chan are intriguing: they found that bride price payments were not associated with husband's help after marriage, but dowry payments were. It is possible that whereas in Uganda men use bride price to buy their wife's sexual fidelity, in Taiwan they buy the right not to help with household chores. In both cases, bride price seems to buy men a way to obtain services from their wives without the need to reciprocate.

To the extent that further research can establish causality more firmly, our analysis carries policy implications. It follows from our theoretical analysis that the elimination of a bride price system, or the weakening of such system via the elimination of refundability, may encourage men to find other ways of obtaining their wife's fidelity, including reciprocation. Reform-minded Ugandans may adapt Solomon's Proverb as follows:

Who can find a virtuous woman? A virtuous man, for rubies no longer buy virtue.

ACKNOWLEDGEMENTS: Helpful comments were received from two anonymous referees, Stephane Mechoulan, Catherine Sofer, and Howard Yourow. 


\section{REFERENCES}

Anderson S (2003) Why dowry payments declined with modernization in Europe but are rising in India. Journal of Political Economy 111(2):269-310.

Arunachalam R, Logan T (2006) On the heterogeneity of dowry motives. NBER Working Paper No. W12630

Becker G (1973) A theory of marriage i. Journal of Political Economy 81(4):813-846.

Becker GS (1981) A treatise on the family. Second Edition, Harvard University Press, Cambridge

Bishai D, Grossbard S (2007) Technical appendix to far above rubies. Hopkins Population Center Working Paper Series 2007(July 18, 2007):

Bishai D, Pariyo G, Ainsworth M, Hill K (2004) Determinants of personal demand for an AIDS vaccine in Uganda. Bulletin Of The World Health Organization 82(9):652-660.

Bishai D, Patil P, Pariyo G, Hill K (2006) The Babel effect: Community linguistic diversity and extramarital sex in Uganda. AIDS and Behavior 10(4):369-76.

Botticini M (1999) A loveless economy? Intergenerational altruism and the marriage market in a tuscan town, 1415-1436. Journal of Economic History 59(1):104-21.

Botticini M, Siow A (2003) Why dowries? The American Economic Review 93(4):1385-1398.

Bronfenbrenner M (1971) A note on the economics of the marriage market. Journal of Political Economy 79(6):1424-1425.

Cameron S (2002) The economics of partner out trading in sexual markets. Journal of Bioeconomics 4(3):195-222.

Caudill S (1988) An advantage of the linear probability model over probit or logit. Oxford Bulletin of Economics and Statistics 50(4):425-7.

Choo E, Siow A (2006) Who marries whom and why. Journal of Political Economy 114(1):175-201.

Cigno A (1990) Economics of the family. Clarendon Press, Oxford

Fair RC (1978) A theory of extramarital affairs. Journal of Political Economy 86(1):45-61.

Goldschmidt W (1974) The economics of brideprice among the Sebei and in East Africa. Ethnology 13(3):313-331.

Government of Uganda (2001) A compendium of laws relating to domestic relations in Uganda. LDC Publishers, Kampala

Grossbard A (1978) Towards a marriage between economics and anthropology and a general theory of marriage. American Economic Review 68(2):33-37.

Grossbard-Shechtman A (1983) On the role and determinants of bride price: Comment. Current Anthropology 24(2):210.

Grossbard-Shechtman S (1993) On the economics of marriage. Westview Press, Boulder, CO

Jacoby HG (1995) The economics of polygyny in sub-saharan africa: Female productivity and the demand for wives in Cote d'Ivoire. Journal of Political Economy 103(5):938-71.

Kaye DK, Mirembe F, Ekstrom AM, Kyomuhendo GB, Johansson A (2005) Implications of bride price on domestic violence and reproductive health in Wakiso district, Uganda. Afr Health Sci $5(4): 300-3$

Kimuna S, Djamba Y (2005) Wealth and extramarital sex among men in Zambia. Int Fam Plan Perspect 31(2):83-9.

Kirungi WL, Musinguzi J, Madraa E, Mulumba N, Callejja T, Ghys P, Bessinger R (2006) Trends in antenatal HIV prevalence in urban Uganda associated with uptake of preventive sexual behaviour. Sex Transm Infect 82 Suppl 1(i36-41.

Kressel GM (1977) Bride-price reconsidered. Current Anthropology 18(3): 441-458.

Laferrere A (2001) Marriage settlements. Scandinavian Journal of Economics 103(485-504. 
Lam D (1988) Marriage markets and assortative mating with household public goods. Journal of Human Resources 24(4)(462-487.

Lemennicier B (1988) Le marche du mariage et du famille. Presses Universitaires de France, Paris

Mennill DJ, Boag PT, Ratcliffe LM (2003) The reproductive choices of eavesdropping female blackcapped chickadees, poecile atricapillus. Naturwissenschaften 90(12):577-82.

Mosher WD, Chandra A, Jones J (2005) Sexual behavior and selected health measures: Men and women 15-44 years of age, united states, 2002. Adv Data 362):1-55.

Nzita R, Niwampa M (1998) Peoples and cultures of Uganda. Fountain Publishers, Kampala

Okioma M (2004) Brideprice--paving the way for a killer. International Conference on Brideprice and Development 2004(April 11):

Onah HE, Iloabachie GC, Obi SN, Ezugwu FO, Eze JN (2002) Nigerian male sexual activity during pregnancy. Int J Gynaecol Obstet 76(2):219-23.

Papps I (1980) For love or money? A preliminary economic analysis. Hobart Paperback, London

Papps I (1983) The role and determinants of bride-price: The case of a Palestinian village. Current anthropology. Current Anthropology 24(2):203-215.

Parikh S (2007) The political economy of marriage and HIV: The ABC approach, "Safe" Infidelity, and managing moral risk in Uganda. American Journal of Public Health 97(7):1198-1208.

Rao V (1993) The rising price of husbands: A hedonic analysis of dowry increases in rural India. Journal of Political Economy 101(4):666-677.

Rogers N (2004) The human and economic costs of bride price in Buganda. International Conference on Brideprice and Development 2004(April 11):

Slaymaker E, Buckner B (2004) Monitoring trends in sexual behaviour in Zambia, 1996-2003. Sex Transm Infect 80 Suppl 2(ii85-90.

Trivers RL (1972) Parental investment and sexual selection. In Cambell B (ed) Sexual selection and the descent of man. Aldine de Gruyter, New York

Uganda Bureau of Statistics (2000) Statistical abstract. Government of Uganda, Entebbe, Uganda

Uganda Bureau of Statistics and ORC Macro (2001) Uganda demographic and health survey 20002001. UBOS and ORC Macro, Calverton, MD

Weiss Y, Willis RJ (1985) Children as collective goods and divorce settlements. Journal of Labor Economics 3(3): 268-292.

Wendo C (2004) African women denounce bride price. Campaigners claim payment for wives damages sexual health and contributes to AIDS spread. Lancet 363(9410):716.

Willis RJ (1999) A theory of out of wedlock childbearing. Journal of Political Economy 107(6):S33-S64.

Yen ST (1999) Nonparticipation and corner solution: Extramarital affairs reconsidered. Applied Economic Letters 6(7):443-445.

Zhang J, Chan W (1999) Dowry and wife's welfare: A theoretical and empirical analysis. Journal of Political Economy 107(4):786-808. 
Table 1 Means, Percent, and Standard Deviations (in Parentheses)

$\begin{array}{ccccc}\text { Whole Sample } & \text { Wives with no } & \text { Wives with } & \text { Wives with bride } & \text { Wives without bride } \\ \text { infidelity } & \text { infidelity } & \text { price } & \text { price }\end{array}$

Number of observations

552

526

26

376

178

\section{VARIABLES}

$\%$ Infidelity reported by wives in last 12 mo.

5

0

100

2

10

$\%$ Infidelity reported by husbands in last $12 \mathrm{mo}^{1}$

$\%$ Paid bride price

68

69

35

100

0

\section{Wife's characteristics}

Age

Schooling in years ${ }^{2}$

\% Perceives HIV not possible

$$
23
$$

24

8

27

15

\section{Husband's Characteristics}

Age

$\begin{array}{cc}38.15(12.25) & 38.38(12.27) \\ 5.52(3.13) & 5.52(3.11) \\ .52(1.63) & .5(1.63) \\ 56 & 57\end{array}$

$33.4(11.12)$

$39.38(12.72)$

$35.56(10.79)$

Schooling in years ${ }^{2}$

Number of months away in last

12 months

\% Farmer

56

$5.46(3.67)$

$5.52(3.02)$

$5.52(3.35)$

$.73(1.59)$

$0.40(1.42)$

0.75 (1.98)

\section{Household Characteristics}

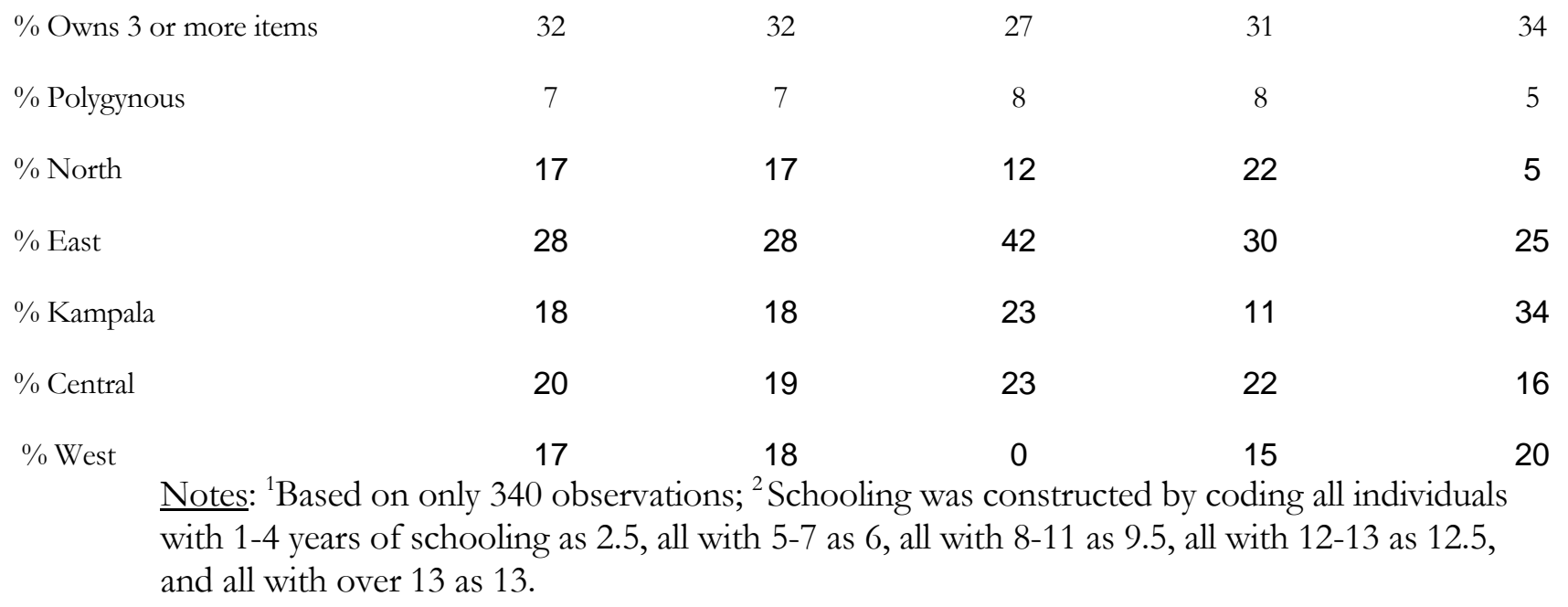


Table 2 OLS Regressions of Wife's Infidelity, Husband's Infidelity, and Bride Price

\begin{tabular}{|c|c|c|c|c|}
\hline & \multirow{2}{*}{$\begin{array}{l}\text { Wife's } \\
\text { Infidelity } \\
\text { A }\end{array}$} & \multirow{2}{*}{$\begin{array}{l}\text { Husband's } \\
\text { Infidelity }\end{array}$} & \multicolumn{2}{|c|}{ Wife Had Bride Price } \\
\hline & & & $\mathrm{C}$ & $\mathrm{D}$ \\
\hline Wife Had Bride Price & $\begin{array}{c}-0.087 \\
(-2.73)^{* * *}\end{array}$ & $\begin{array}{l}0.078 \\
(1.33)\end{array}$ & & \\
\hline $\begin{array}{l}\text { Wife's Characteristics } \\
\text { Wife's Schooling }\end{array}$ & $\begin{array}{c}0.015 \\
(1.98)^{* *}\end{array}$ & $\begin{array}{l}0.028 \\
(1.52)\end{array}$ & $\begin{array}{l}0.007 \\
(0.41)\end{array}$ & $\begin{array}{l}0.002 \\
(0.10)\end{array}$ \\
\hline Square of Wife's Schooling & $\begin{array}{l}-0.002 \\
(-1.90)^{*}\end{array}$ & $\begin{array}{l}-0.002 \\
(-1.04) \\
\end{array}$ & $\begin{array}{c}0 \\
(-0.32) \\
\end{array}$ & $\begin{array}{c}0 \\
(-0.03) \\
(\end{array}$ \\
\hline Wife's Age & $\begin{array}{c}0 \\
(-0.01) \\
\end{array}$ & $\begin{array}{l}-0.003 \\
(-0.82) \\
\end{array}$ & $\begin{array}{l}0.004 \\
(1.41)\end{array}$ & $\begin{array}{l}0.004 \\
(1.40)\end{array}$ \\
\hline Wife perceives no risk of AIDS & $\begin{array}{l}-0.022 \\
(-1.47) \\
\end{array}$ & $\begin{array}{l}-0.069 \\
(-1.41) \\
\end{array}$ & $\begin{array}{c}0.103 \\
(2.19)^{* *} \\
\end{array}$ & $\begin{array}{c}0.101 \\
(2.01)^{* *} \\
\end{array}$ \\
\hline Husband's Characteristics & & & & \\
\hline $\begin{array}{l}\text { Husband's Schooling } \\
\text { Square of Husband's Schooling } \\
\text { Husband is a Farmer }\end{array}$ & $\begin{array}{c}-0.02 \\
(-1.58) \\
0.002 \\
(1.47) \\
-0.04 \\
(-1.30) \\
\end{array}$ & $\begin{array}{l}-0.039 \\
(-1.80)^{*} \\
0.003 \\
(1.72)^{*} \\
-0.067 \\
(-1.43) \\
\end{array}$ & $\begin{array}{c}0.035 \\
(1.60) \\
-0.002 \\
(-0.91) \\
0.142 \\
(2.53)^{* *}\end{array}$ & $\begin{array}{c}0.036 \\
(1.60) \\
-0.002 \\
(-0.90) \\
0.144 \\
(2.54)^{* *} \\
\end{array}$ \\
\hline Husband's Age & $\begin{array}{l}-0.001 \\
(-0.76)\end{array}$ & $\begin{array}{l}-0.003 \\
(-0.86)\end{array}$ & $\begin{array}{l}0.002 \\
(1.13)\end{array}$ & $\begin{array}{l}0.002 \\
(1.01)\end{array}$ \\
\hline Number of months husband was away in last 12 Mos. & $\begin{array}{l}0.004 \\
(0.75)\end{array}$ & $\begin{array}{l}0.005 \\
(0.26)\end{array}$ & & \\
\hline Household Characteristics & & & & \\
\hline Household Owns 3 or More Items & $\begin{array}{l}-0.021 \\
(-1.13) \\
\end{array}$ & $\begin{array}{l}-0.042 \\
(-0.73) \\
\end{array}$ & $\begin{array}{l}0.044 \\
(1.02)\end{array}$ & $\begin{array}{l}0.047 \\
(1.06)\end{array}$ \\
\hline North & $\begin{array}{l}0.008 \\
(0.34)\end{array}$ & $\begin{array}{l}-0.122 \\
(-1.84)^{*}\end{array}$ & $\begin{array}{l}0.071 \\
(1.18)\end{array}$ & $\begin{array}{c}0.214 \\
(2.60)^{* *}\end{array}$ \\
\hline East & $\begin{array}{l}0.016 \\
(0.53)\end{array}$ & $\begin{array}{c}-0.05 \\
(-0.82) \\
\end{array}$ & $\begin{array}{l}-0.054 \\
(-1.01) \\
\end{array}$ & $\begin{array}{l}-0.04 \\
(-0.72) \\
\end{array}$ \\
\hline Kampala & $\begin{array}{l}-0.03 \\
(-0.83) \\
\end{array}$ & $\begin{array}{l}-0.162 \\
(-1.58) \\
\end{array}$ & $\begin{array}{c}-0.33 \\
(-4.61)^{* * *}\end{array}$ & $\begin{array}{c}-0.257 \\
(-3.63)^{* * *} \\
\end{array}$ \\
\hline Polygynous Household & $\begin{array}{l}-0.006 \\
(-0.15) \\
\end{array}$ & $\begin{array}{l}0.047 \\
(0.34)\end{array}$ & $\begin{array}{l}0.054 \\
(0.66)\end{array}$ & $\begin{array}{l}0.018 \\
(0.21)\end{array}$ \\
\hline West & $\begin{array}{c}-0.144 \\
(-3.97) * * * \\
\end{array}$ & $\begin{array}{c}-0.201 \\
(-2.78)^{* * *} \\
\end{array}$ & $\begin{array}{l}-0.091 \\
(-1.29) \\
\end{array}$ & $\begin{array}{l}0.183 \\
(1.86)^{*}\end{array}$ \\
\hline Interaction of West and Had Bride Price & $\begin{array}{c}0.113 \\
(3.23)^{* * *} \\
\end{array}$ & $\begin{array}{c}0.01 \\
(0.11)\end{array}$ & & \\
\hline Constant & $\begin{array}{c}0.222 \\
(3.33)^{* * *}\end{array}$ & $\begin{array}{c}0.531 \\
(3.99)^{* * *}\end{array}$ & $\begin{array}{c}0.293 \\
(2.43)^{* *}\end{array}$ & $\begin{array}{l}0.201 \\
(1.52)\end{array}$ \\
\hline Number of Observations & 552 & 344 & 590 & 578 \\
\hline R-squared & 0.07 & 0.09 & 0.15 & 0.17 \\
\hline Controls for ethnicity & no & no & no & yes \\
\hline
\end{tabular}

Notes: Robust t-statistics in parentheses; ${ }^{*}$ significant at $10 \%$; $*$ significant at $5 \%$; $* * *$ significant at $1 \%$. 

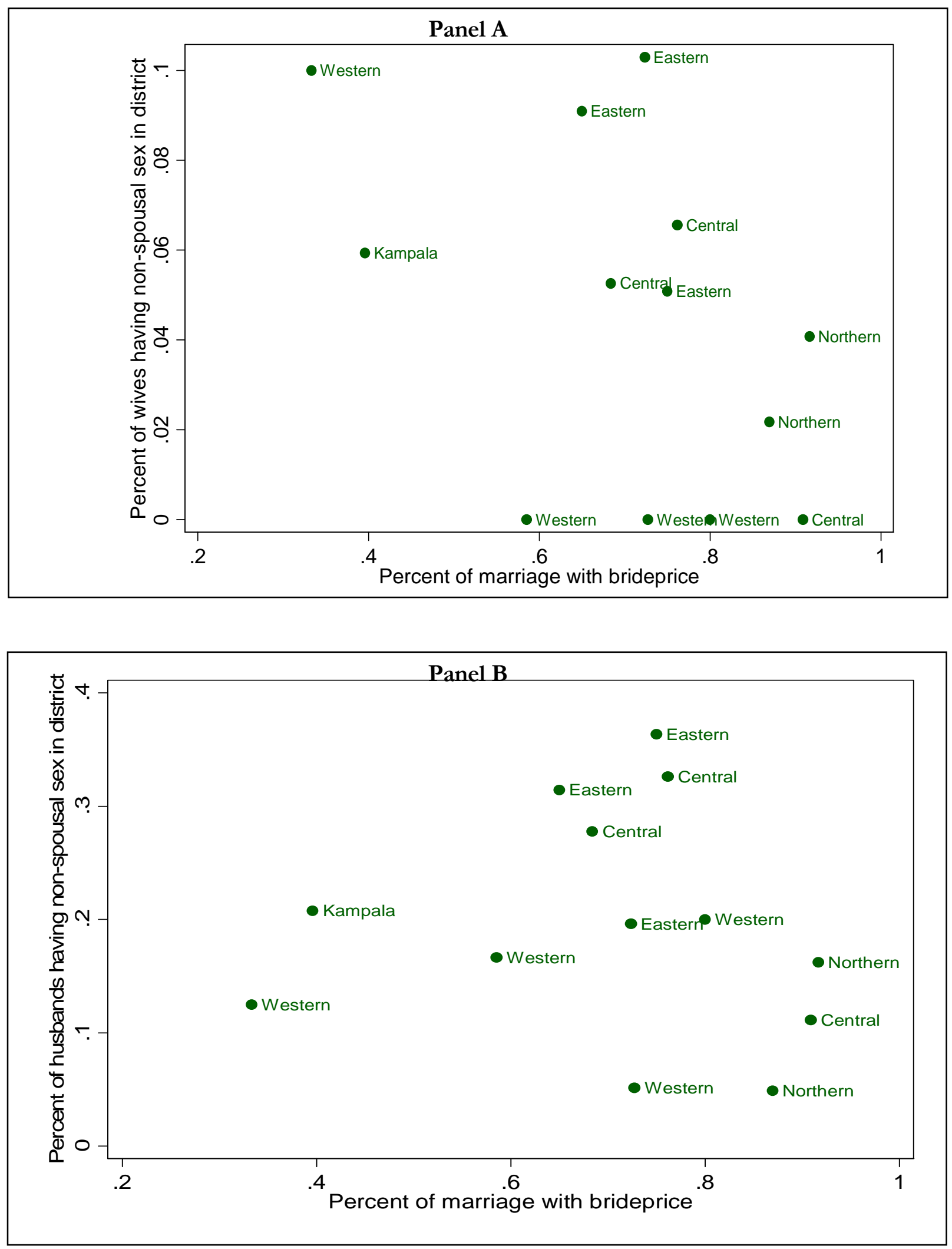

Figure 1. District level correlations between bride price prevalence and rates of non-spousal sexual contact reported by wives (Panel A) and husband's (Panel B). Labels on each point indicate the general region of Uganda in which the district lies. Kampala is exclusively urban. 